Jurnal Pilar Teknologi, Volume 3 Nomor 2 Edisi September 2018

ISSN Print : 2502-7042 ISSN Online : 2580-3557

http://pilar.unmermadiun.ac.id

\title{
Pengembangan Website Informasi Hama Wereng
}

\author{
Arief Budiman ${ }^{1}$, Pradityo Utomo ${ }^{2}$

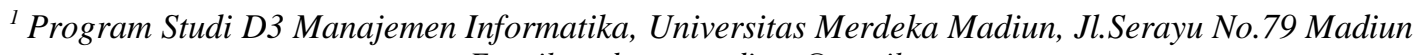 \\ E-mail: andreas_rendiana@gmail.com \\ ${ }^{2}$ Program Studi D3 Manajemen Informatika, Universitas Merdeka Madiun, Jl.Serayu No.79 Madiun \\ E-mail: pradityo@unmer-madiun.ac.id
}

\begin{abstract}
In Indonesia, rice is still an essential commodity. Besides as a crop producing staple food for rice, also as a source of eyes the primary search for farmers. Problems that are often experienced by farmers are the threat of pest attacks. If not handled quickly and correctly suffered a massive loss, it can even cause a failed harvest finally harming farmers. In Madiun Regency, the total rice fields are planted hopper infestation before the 2017 rainy season harvest reaching 223 hectares covering Pilangkenceng Subdistrict, Wonoasri, Balerejo, Sawahan, Mejayan, Saradan, and Wungu. So far to suppress attacks Planthopper pests, farmers, give stimulant pesticides to plants that if Improper handling will interfere with health. The best solution is to recognize the initial attack of pests so that the level of attack on plants can be minimized. The limited knowledge and skills of partner farmers in identifying their paddy plants early makes farmers prefer the fast way by spraying pesticides. This Community Service aims to motivate farmers to avoid using pesticides by providing quick and easy and attractive solutions in early detection rice crop pests. To facilitate farmers in detecting pest attacks, a website was developed which contained information about planthopper pest attacks and how to overcome them by using biological agents. Website developed can be used by farmers by accessing it through a browser on a computer device or smartphone device.
\end{abstract}

Keywords : Website, Pest, Rice, Farmers.

\section{PENDAHULUAN}

Indonesia seharusnya mampu membantu pemasukan devisa negara dan memperbaiki perekonomian masyarakat yang bersumber dari bidang pertanian. Tetapi kenyataannya tahun 2016 jumlah petani menurun, sehingga berdampak pada berkurangnya ketersediaan produksi pangan. Berdasarkan survei Badan Pusat Statistik tahun 2013, jumlah petani telah mengalami penyusutan menjadi 26,13 juta, yang 10 tahun sebelumnya berjumlah 31,17 juta (jpnn, 2015). Salah satu faktor yang menyebabkan menurunnya jumlah petani adalah sulitnya pengelolaan pertanian, khususnya tanaman padi.

Kabupaten Madiun adalah salah satu wilayah dari Provinsi Jawa Timur yang sebagian penduduknya bermata pencaharian sebagai petani. Permasalahan yang dihadapi petani adalah akibat serangan hama. Pada tahun 2017, Dinas Pertanian dan Perikanan Kabupaten Madiun telah mencatat lahan sawah yang terserang hama seluas 223 hektar berdampak pada penurunan hasil produksi padi. Hal tersebut tampak pada hasil panen hanya sekitar 2,5 sampai 3 ton yang seharusnya dapat memanen 6 ton padi, Menurut Kabid Tanaman Pangan, Dinas
Pertanian dan Perikanan (Disperta) Kabupaten Madiun, wilayah yang terserang hama antara lain Sawahan (Yud, 2017).

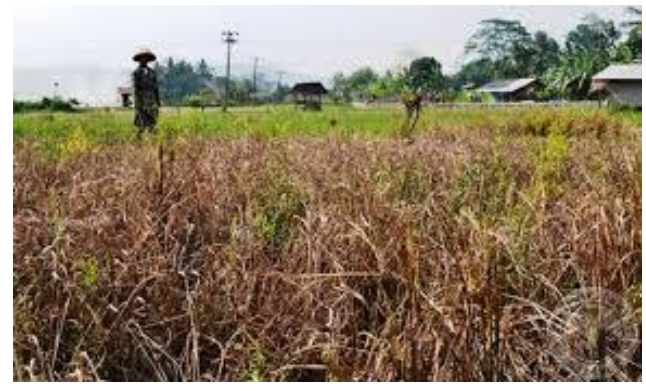

Gambar 1.1. Sawah Akibat Serangan Hama

Gambar 1 menunjukkan salah satu contoh sawah yang terserang hama di salah satu wilayah Kabupaten Madiun. Adanya serangan hama menyebabkan banyak petani yang mengalami kerugian karena hasil panen kurang maksimal, sehingga tidak sedikit petani yang beralih ke mata pencaharian lain. Jika petani banyak yang beralih profesi, tidak menutup 
kemungkinan harga beras dapat melambung tinggi, disebabkan padi yang dihasilkan dari dalam negeri hanya sedikit. Padahal Indonesia merupakan negara agraris yang kaya akan sumber daya alam, yang seharusnya mampu mengelola kekayaan yang dimiliki. Ancaman serangan hama padi, dapat membuat tradisi budaya bertani di Indonesia khususnya pedesaan dapat hilang. Kondisi ini tidak menutup kemungkinan bagi pemerintah akan melakukan import beras..Berdasarkan permasalahan serangan hama khususnya pada tanaman padi, pemerintah seharusnya ikut serta dalam penanganan problematika yang dialami petani.dengan memberikan himbauan kepada para petani agar dapat mengidentifikasi dini serangan hama.

Petani Indonesia sedang mengalami ancaman serangan hama tanaman padi Salah satu wilayah Kabupaten Madiun yang sudah terserang hama yaitu Kecamatan Sawahan. Akibat serangan hama pada tanaman padi berdampak pada penurunan produktivitas dan pendapatan petani. Saat ini petani selalu terlambat mengetahui serangan. Umumnya serangan diketahui petani setelah tanaman rusak parah atau hampir mati. Serangan hama pada tanaman padi sangat cepat menyebar sehingga kerusakan semakin meluas. Penanganan yang dilakukan petani hanya dengan penyemprotan pestisida. Cara penyemprotan kurang maksimal hasilnya jika dilakukan setelah serangan hama sudah mewabah.

Permasalahan yang dihadapi masyarakat adalah keterbatasan pengetahuan mengenai identifikasi serangan hama tanaman padi serta kurang cepatnya dalam melakukan identifikasi awal dari serangan hama. Dalam melakukan identifikasi hama dikarenakan mitra selalu menunggu informasi dari para penyuluh pertanian, sehingga penanganannya sering terlambat. Selain itu mitra lebih mengandalkan penanganan hama dengan menggunakan pestisida yang cepat dan mudah. Hal yang dapat dilakukan untuk mengatasi permasalahan-permasalahan tersebut adalah dengan membangun sebuah sistem yang dapat memberikan informasi-informasi mengenai Hama Wereng kepada petani Padi.

\section{METODE PENELITIAN}

Internet berasal dari kata Interconnection Networking yang mempunyai arti hubungan berbagai komputer dengan bermacam tipe yang membentuk system jaringan yang mencakup seluruh dunia melalui jalur komunikasi seperti telepon. Komponen yang mengatur integrasi dan komunikasi jaringan computer ini adalah protokol-protokol yang umum disebut TCP/IP. TCP (Transmission Control Protocol) akan memastikan bahwa semua hubungan bekerja dengan benar, sedangkan IP (Internet Protocol) akan mentransmisikan data dari satu komputer ke komputer lain. TCP/IP secara umum berfungsi untuk memilih rute alternatif jika suatu rute tidak dapat digunakan,mengatur dan mengirimkan paketpaket pengiriman data dan lain-lain. (Fiati, 2005).

Website merupakan kumpulan dari halamanhalaman web yang berhubungan dengan file-file lain yang saling terkait. Dalam sebuah website terdapat suatu halaman yang dikenal dengan sebutan home page. Home page adalah sebuah halaman yang pertama kali dilihat ketika seseorang mengunjungi sebuah website. Dari home page, pengunjung dapat mengklik hyperlink untuk pindah ke halaman lain yang terdapat dalam website tersebut. (Johnsen, 2004). Dalam membangun sebuah web tentunya sebelumnya kita memiliki sebuah tujuan, apakah untuk media promosi, media pembelajaran, menjual suatu produk, atau mungkin hanya untuk sekedar tampil di internet, dengan kita memiliki sebuah tujuan maka akan berpengaruh pada desain web yang kita buat. Dalam mendesain web kita harus bisa menentukan mana jenis web yang akan kita buat, kalau web kita tidak ingin di update atau tidak ingin ada interaksi antar pengunjung,maka web yang kita buat termasuk web statis, sedangkan kalau web yang kita buat bias di update secara berkala atau adanya interaksi antar pengunjung,maka web anda termasuk web dinamis. Tentunya diperlukan bahasa pemrograman tertentu untuk bisa menciptakan web yang dinamis. Bahasa pemrograman yang biasa digunakan untuk membuat web dinamis antara lain : JSP,ASP.PHP dan Cold Fusion (Juju, 2006).

PHP adalah singkatan dari PHP Hypertext Preprocessor yang digunakan sebagai bahasa script serverside dalam pengembangan web yang disisipkan pada dokumen HTML (Peranginangin, 2006). PHP adalah bahasa server-side scripting yang menyatu dengan HTML untuk membuat halaman web yang dinamis.maksud dari server side scripting adalah sintaks dan perintah perintah yang diberikan akan sepenuhnya dijalankan di server tetapi disertakan pada dokumen HTML.. Ketika seorang pengguna internet akan membuka suatu situs yang menggunakan fasilitas server side scripting PHP, maka terlebih dahulu server yang bersangkutan akan memproses semua perintah PHP di server lalu mengirimkan hasilnya dalam format HTML ke web browser pengguna internet tadi,dengan demikian seorang pengguna internet tidak dapat melihat kode program yang ditulis dalam PHP sehingga keamanan dari halaman web menjadi lebih terjamin (Sunarfrihantono, 2003).

PHP merupakan bahasa skrip yang digunakan untuk membuat halaman web yang dinamis,PHP bersifat open source product,PHP bersifat server side scripting yang dapat ditambahkan ke dalam HTML. (Ramadhan dan saputra, 2005) PHP merupakan bahasa scripting yang menyatu dengan tagtag HTML dalam satu file, dieksekusi di server, dan digunakan untuk membuat halaman web yang dinamis (Adam, 2004). MySQL adalah multiuser database yang menggunakan bahasa Structured Query Language (SQL).

MySQL dalam operasi client-server melibatkan server daemon MySQL di sisi server dan berbagai macam program serta library yang berjalan di sisi client. SQL adalah bahasa standar yang digunakan untuk mengakses database server ( Sunarfrihantono, 2003). MySQL ialah database server yang mampu menampung sampai ratusan giga record. MySQL juga merupakan aplikasi yang free atau gratis. (Pramono dan Syafii, 2005).

Pemrograman merupakan bahasa pemrograman yang dijalankan aplikasinya melalui media web.Ada yang menyebutkan bahwa pemrograman web juga scripting,karena bahasa yang digunakan berupa script tapi intinya sama.(Prihatna, 2005).

HTML terdiri dari tag-tag yang fungsinya untuk membuat dokumen menjadi dapat dibaca oleh browser,HTML merupakan script dimana kita bisa menampilkan informasi dan daya kreasi kita lewat internet,HTML merupakan bahasa pemrograman fleksibel dimana kita bisa meletakkan script 
dari bahasa pemrograman lain seperti java, visual basic, c++ dan lain-lain. (Prihatna, 2005).

Browser adalah sebuah program yang digunakan untuk menampilkan halaman web. Browser berkomunikasi dengan web server melalui protocol HTTP, yang membaca dan menerjemahkan bahasa HTML dan data gambar untuk ditampilkan secara visual sehingga informasi yang ada dapat dibaca. (Prihatna, 2005).

Wereng adalah sebutan umum untuk serangga penghisap cairan tumbuhan anggota ordo Hemiptera (kepik sejati), subordo Fulgomorpha, khususnya berukuran kecil. Ukuran hama wereng jantan 2-3 mm, sedangkan ukuran hama wereng betina 3-4 mm. Hama wereng dapat bertelur sebanyak 100500 butir. Disamping ukuran yang sangat kecil, hama jenis inipun populasinya sangat cepat, bahkan seekor wereng betina ketika bertelur mampu menghasilkan 100-500 telur dan juga pada suhu $25^{\circ} \mathrm{C}$, wereng juga mampu hidup hingga mencapai umur 30 hari (Hadi, 2009). Serangan awal Hama Wereng dapat dilihat seperti pada gambar 2.1 dan Gambar 2.2 berikut.

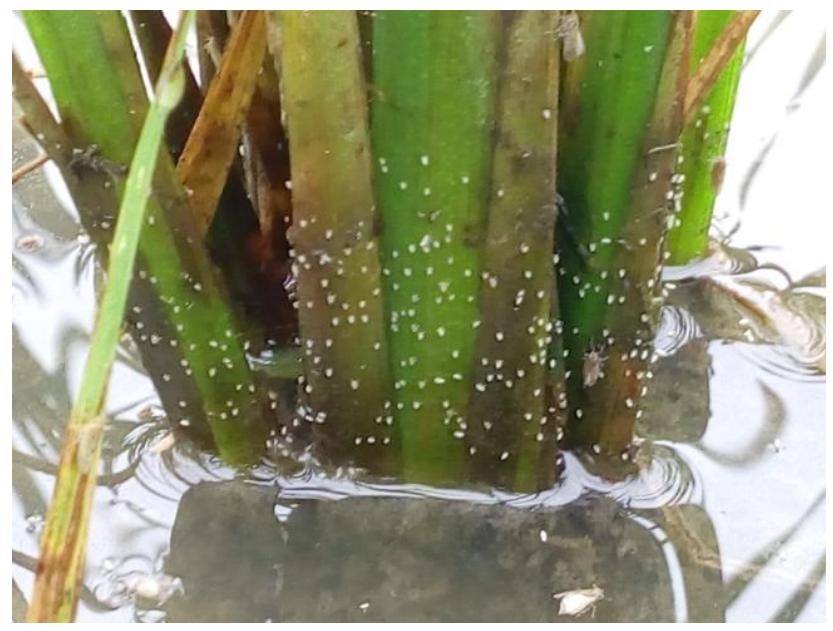

Gambar 2.1. Serangan Awal Hama Wereng

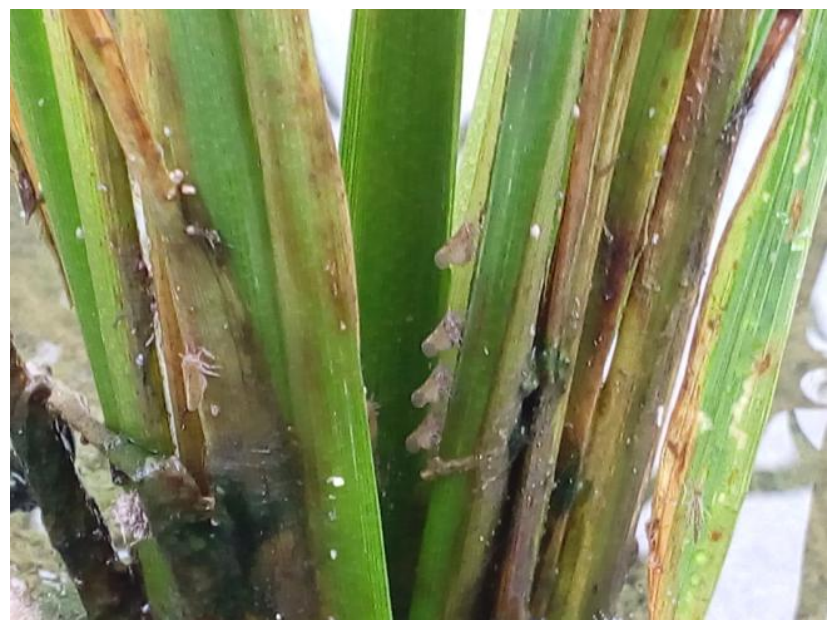

Gambar 2.2. Serangan Wereng Dewasa dan Sudah Menimbulkan Jelaga Pada Batang Tanaman Padi.

Dalam penelitian ini yang akan dilakukan adalah membangun sistem informasi SDN Paron 02 berbasis web. Dipilih berbasis web,karena di era ini masyarakat telah mengenal internet dan hampir dalam kehidupan sehari-hari masyarakat memanfaatkan internet untuk mencari informasi dari dalam negeri maupun luar negeri. Dengan memanfaatkan internet, masyarakat tidak harus datang langsung ke sekolah hanya untuk mendapatkan informasi yang diinginkan. Sistem informasi SDN Paron 02 dibangun dengan memanfaatkan internet, bertujuan mempermudah masyarakat dalam mencari informasi tentang informasi SDN Paron 02. Adapun metode pengembangan sistem dalam membuat penelitian dapat dilihat pada Gambar 1 .

Metode penelitian yang digunakan mengadopsi metode pengembangan website www.werengmania.com menggunakan model Build And Fix. Dengan menggunakan metode Build And Fix mampu melakukan pengembangan aplikasi yang meliputi pembuatan dan perbaikan tanpa membutuhkan waktu yang lama berbulan-bulan. Adapun tahapan dari metode Build And Fix dapat dapat dilihat pada Gambar 3.1.

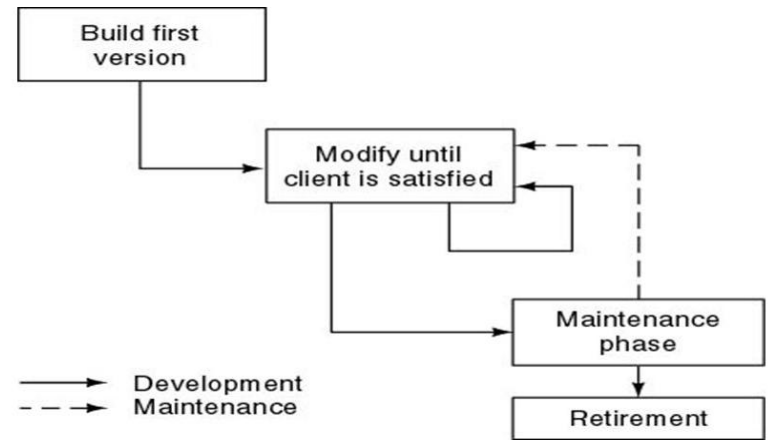

Gambar 3.1. Build And Fix Method

Pada Gambar 3.1 telah ditampilkan dari metode Build And Fix dalam pengembangan aplikasi. Tahapan yang pertama adalah Build First Version, dimana aplikasi dibuat versi pertama berdasarkan kebutuhan-kebutuhan dan penjelasan dari customer yang dalam hal ini melibatkan user. User adalah pihak yang akan menggunakan aplikasi. Setelah aplikasi selesai dibuat bersi pertama, selanjutnya tahapan Modify Until Client Customer Satisfied. Pada tahapan ini, user melakukan evaluasi terhadap aplikasi awal yang telah dibuat. User juga memberikan komentar jika terjadi perbedaan pendapat terhadap aplikasi yang diinginkan user. Jika terjadi ketidak puasan user, maka programer akan memperbaiki aplikasi sampai menjadi aplikasi fix sesuai dengan harapan dan kebutuhan user.

Tahapan ketiga adalah Maintenance. Tahap Maintenance akan dilakukan jika aplikasi yang sudah selesai, ternyata terdapat eror atau kerusakan saat implementasi. Dengan menggunakan metode Build And Fix, maka programer berkewajiban melakukan perbaikan sampai user terpuaskan dengan aplikasi yang telah dibuat. Tahapan yang terakhir adalah Retirement. Retirement merupakan tahapan saat user sudah tidak menggunakan aplikasi yang dibuat programmer. Sehingga model Build And Fix ini cocok untuk pembuatan aplikasi yang pengerjaannya dalam waktu yang cukup singkat.

Selain metode pengembangan aplikasi, penelitian ini menggunakan metode Black Box untuk pengujian aplikasi. Pengujian Black Box lebih mengarah pada fungsionalitas aplikasi. Beberapa keuntungan menggunakan pengujian Black Box antara lain :

1. Ketepatan fungsional aplikasi 
2. Ketepatan antarmuka aplikasi

3. Ketepatan struktur data aplikasi

4. Ketepatan basis data

5. Ketepatan performa aplikasi

\section{Build First Version}

Pada tahap pertama pengembangan website adalah dengan menyusun versi awal dari website www.werengmania.com. Versi awal website dikembangkan dengan menggunakan Wordpress, Wordpress di install pada local server dengan menggunakan Apache Server dan Database MySQL. Website dikembangkan dengan menggunakan fitur-fitur dan tampilan standar dari Wordpress, pada tahap ini juga dilakukan pengisian data-data atau informasi yang perlu ditampilkan melalui website begitu juga dengan konfigurasi menu-menu pada tampilan website. Untuk struktur antarmuka sistem dapat dilihat pada gambar 3.2.

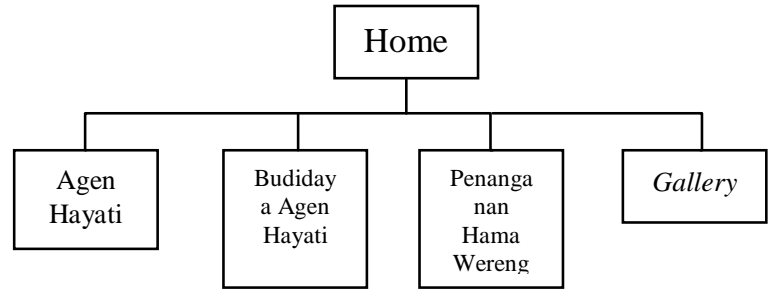

Gambar 3.2. Struktur Antarmuka Sistem

\section{Modify Until Client Customer Satisfied}

Setelah selesai membangun versi awal website langkah selanjutnya adalah dengan melakukan penyesuaianpenyesuaian tampilan dari website. Pada tahap ini dilakukan perubahan fitur Themes atau tema yang digunakan oleh website. Perubahan tema dilakukan dengan memperhatikan dari faktor keseuaian antara konten website dengan tema. Penyesuaian-penyesuaian dilakukan sampai pada kondisi dimana pengguna atau user website merasa cukup sesuai dengan website yang dikembangkan.

\section{Maintenance}

Setelah Website selesai dibangun sesuai dengan permintaan user maka selanjutnya adalah tahap maintenance. Pada tahap ini yang dilakukan adalah pemeliharan website baik dari sisi konten maupun dari sistem pendukung website seperti server dan update framework. Untuk pemeliharaam konten dilakukan dengan cara melakukan pembaharuan konten-konten informasi terkait dengan Hama Wereng dan Cara Penanggulangannya sesuai dengan perkembangan teknologi.

\section{Retirement}

Pada tahap ini, apabila semua proses pengaplikasian website telah selesai secara keseluruhan, dan sudah tidak ada lagi proses pengembangan ataupun pemeliharaan sistem maka siklus telah dinyatakan selesai, sehingga website cukup dijalankan lagi tanpa ada lagi proses update secara sistem. Sedangkan update konten informasi dapat terus dilakukan.

\section{HASIL DAN PEMBAHASAN}

Aplikasi website diletakkan pada server Hosting Masterwebnet dan menggunakan database server MySQL. Aplikasi website dapat diakses melalui browser dengan menggunakan url http://www.werengmania.com, pengguna dapat mengakses melalui browser pada perangkat komputer, laptop, maupun smartphone.

\section{III.1. Halaman Utama Website}

Saat pengguna pertama kali mengakses website melalui url http://www.werengmania.com pengguna akan masuk pada halaman tampilan utama. Pada tampilan utama website akan ditampilkan beberapa menu yang dapat diakses, yaitu menu Home, Agen Hayati, Budidaya Agen Hayati, Cara Penanganan Hama Wereng, Gallery Foto Hama Wereng, Download Aplikasi, dan About. Pada main page halaman utama juga akan ditampilkan informasi umum mengenai Hama Wereng seperti yang ditunjukkan pada gambar 3.1.

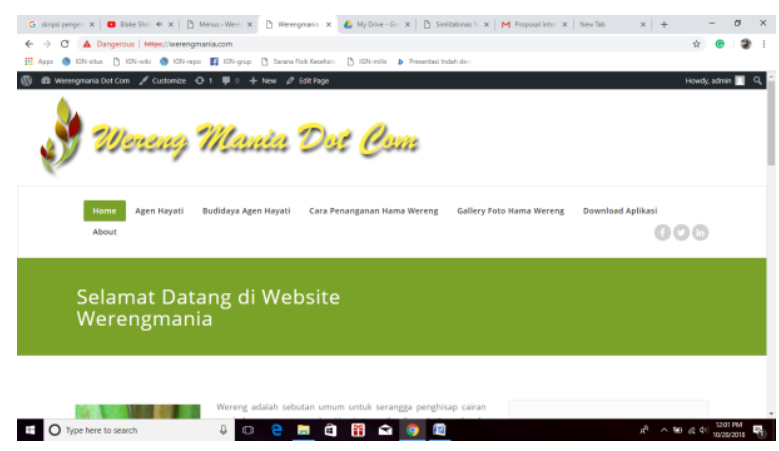

Gambar 3.1 Halaman Utama

III.2. Halaman Agen Hayati

Pada halaman Agen Hayati akan ditampilkan informasi mengenai apa itu Agen Hayati. Pada halaman tersebut akan dijelaskan beberapa contoh Agen Hayati yang dapat digunakan untuk mengatasi atau mengendalikan serangan Hama Wereng pada Tanaman Padi, seperti yang ditunjukkan pada gambar 3.2.

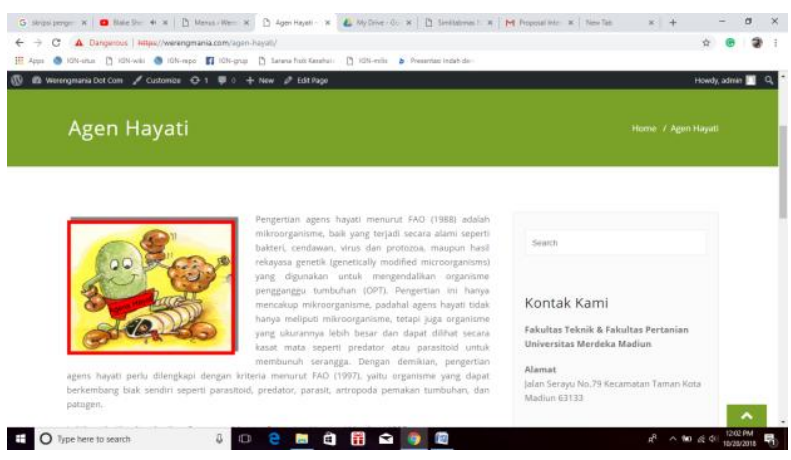

Gambar 3.2. Halaman Agen Hayati

\section{III.3. Halaman Budidaya Agen Hayati}

Pada halaman Budidaya Agen Hayati akan disampaikan informasi-informasi mengenai bagaimana cara untuk dapat membuat Agen Hayati dalam rangka untuk mengendalikan serangan Hama Wereng. Pada halaman tersebut akan dijelaskan lengkap dengan komposisi bahan-bahan yang diperlukan dan bagaimana langkah-langkah pengolahan dari bahan-bahan tersebut, seperti yang ditunjukkan pada gambar 3.3 . 


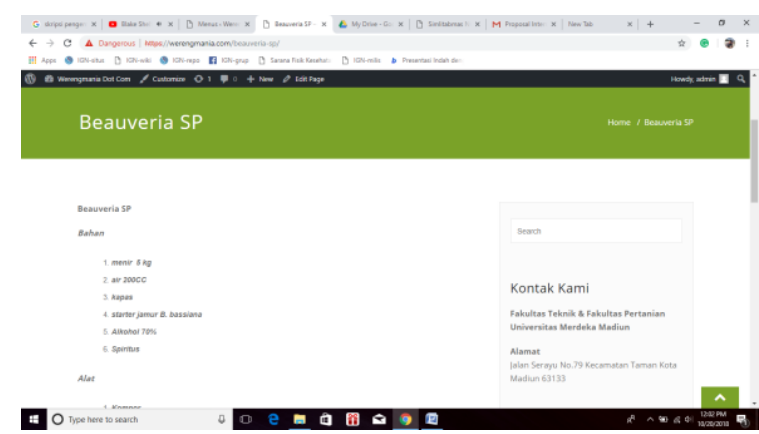

Gambar 3.3. Halaman Budidaya Agen Hayati Beauveria SP

III.4. Cara Penanganan Hama Wereng

Pada halaman Cara Penanganan Hama Wereng akan dijelaskan pada cara membudidayakan Tanaman Padi Sehat sehingga Tanamam Padi tersebut menjadi terhindar dari serangan hama Wereng seperti yang ditunjukkan pada gambar 3.4 .

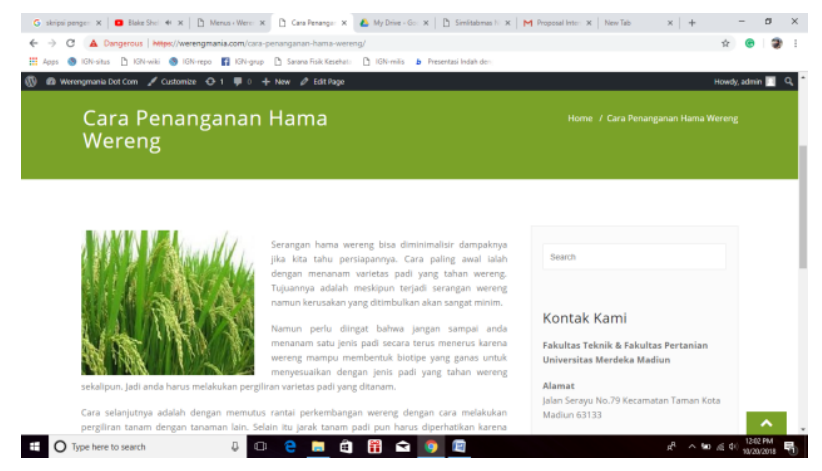

Gambar 3.4. Halaman cara penanganan Hama Wereng

III.5. Halaman Gallery Hama Wereng

Untuk membantu pengguna website ataupun petani Tanaman padi dalam mengenai ciri-ciri serangan Hama Wereng atau Gejala serangan Hama Wereng, dapat dilihat pada Halaman Gallery Foto Hama Wereng seperti pada Gambar 3.5.

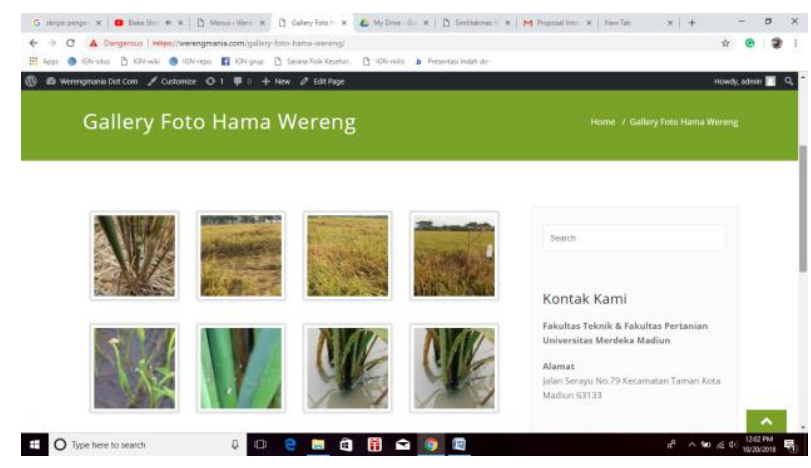

Gambar 3.5. Halaman Gallery Foto Hama Wereng

III.6. Halaman Download Aplikasi

Pada menu download Aplikasi user akan diarahkan ke google drive dimana aplikasi berbasis android untuk deteksi dini serangan hama wereng dibagikan. Disini user dapat mengunduh aplikasi berbasis android untuk dapat diinstal pada perangkat smartphone berbasis Android. Seperti yang ditunjukkan pada gambar 3.6.

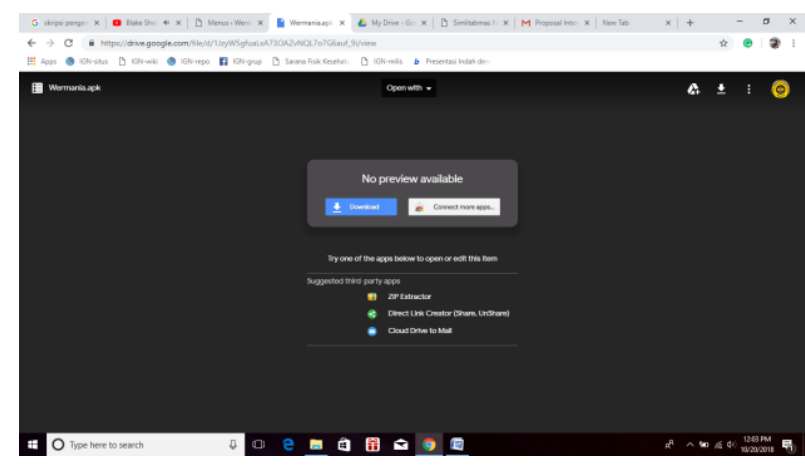

Gambar 3.6. Halaman Download Aplikasi

\section{KESIMPULAN}

IV.1. Kesimpulan

Dari penelitian ini dapat disimpulkan bahwa telah berhasil dikembangkan sebuah Website yang dapat memberikan Informasi-informasi mengenai Hama Wereng pada tanaman Padi sehingga dapat membantu Ptani Padi dalam mengenali serangan awal Hawa Wereng dan bagaimana cara untuk dapat mengatasi serangan Hama Wereng. Melalui website yang dikembangkan Petani Padi juga dapat mengundul Aplikasi Deteksi Dini Hama Wereng berbasis Android yang dapat diaplikasikan pada perangkat Smartphone.

\section{IV.2. Saran}

Untuk penelitian lebih lanjut dapat ditambahkan fitur aplikasi Sistem Pakar serangan Hama Wereng pada tanaman padi ataupun Sistem Pendukung Keputusan waktu penggunaan pupuk atau Agen Hayati agar dapat mewujudkan kondisi lahan pertanian yang sehat sehingga dapat meminimalisir serangan Hama Wereng pada tanaman Padi.

\section{DAFTAR PUSTAKA}

Adam, Andhie, Lala., 2004, PHP \& ProstgreSQL, Yogyakarta: Andi. Arry, Maulana Syarif. 2003. Bedah ActionScript: Menguasai Penulisan Script.

Fiati, Rina., 2005, Akses Internet Via Ponsel, Penerbit ANDI, Yogyakarta.

Hadi, Mochamad., 2009, Biologi InsektaEntomologi, Yogyakarta: Graha Ilmu.

Juju, Dominikus., 2006. Tip dan Trik Desain Web untuk Pemula. Edisil. Jakarta: PT. Elek Media Komputindo.

Johnsen., 2004, WEB DESIGNER untuk PEMULA, Jakarta : Elex Media Komputindo Kelompok Gramedia, Anggota IKAPI.

Peranginangin, Kasiman., 2006. Aplikasi WEB dengan PHP dan MySQL, Yogyakarta: Andi.

Prihatna, Henky., 2005, Kiat Praktis Menjadi Webmaster Profesional, Jakarta : Elex Media Komputindo Kelompok Gramedia, Anggota IKAPI. 
Pramono, Andi., Syafii, M., 2005, Kolaborasi Flash, Dreamweaver, dan PHP untuk Aplikasi Website, Andi. Yogyakarta.

Ramadhan, Arief., Saputra, Hendra., 2005, Buku Latihan PHP 5 \&Mysql, PT Elex Media Komputindo, Jakarta.

Sunarfrihantono, Bimo., 2003 PHP dan MySQL Untuk WEB, ANDI. 